\title{
Removal of arsenate from aqueous media by magnetic chitosan resin immobilized with molybdate oxoanions
}

\author{
K. Z. Elwakeel
}

Received: 4 September 2012/Revised: 16 March 2013/Accepted: 23 April 2013/Published online: 17 May 2013

(C) Islamic Azad University (IAU) 2013

\begin{abstract}
Chitosan was cross-linked using glutaraldehyde in the presence of magnetite. The resin obtained was chemically modified through the reaction with tetraethylenepentamine ligand. The obtained resin was loaded with $\mathrm{Mo}(\mathrm{VI})$ and investigated. The adsorption characteristics of the obtained resin toward $\mathrm{As}(\mathrm{V})$ at different experimental conditions were investigated by means of batch and column methods. The resin showed high affinity and fast kinetics for the adsorption of $\mathrm{As}(\mathrm{V})$ where an uptake value of $1.30 \mathrm{mmol} \mathrm{g}{ }^{-1}$ was reported in $6 \mathrm{~min}$ at $25{ }^{\circ} \mathrm{C}$. Various parameters such as $\mathrm{pH}$, agitation time, $\mathrm{As}(\mathrm{V})$ concentration and temperature had been studied. The kinetics and thermodynamic behavior of the adsorption reaction were defined. These data indicated an endothermic and spontaneous adsorption process and kinetically followed pseudosecond-order model, Fickian diffusion low and Elovich equation. Breakthrough curves for the removal of $\mathrm{As}(\mathrm{V})$ were studied at different flow rates and bed heights. The critical bed height for the studied resin column was found to be $0.656 \mathrm{~cm}$ at flow rate of $4 \mathrm{~mL} \mathrm{~min}^{-1}$. The mechanism of interaction between $\mathrm{As}(\mathrm{V})$ and resin's active sites was discussed. Regeneration and durability of the loaded resin toward the successive cycles were also clarified.
\end{abstract}

Keywords Arsenic (V) removal · Adsorption · Kinetics . Thermodynamics $\cdot$ Column method

K. Z. Elwakeel ( $\square)$

Environmental Science Department, Faculty of Science,

Port-Said University, Port-Said, Egypt

e-mail: Khalid_elwakeel@yahoo.com

\section{Introduction}

Due to the establishment of the toxic effects imposed by the consumption of arsenic-containing drinking water and the reports of elevated arsenic concentrations in numerous water supplies around the world, Arsenic, a contamination, is an issue of serious concern because it has been posing a health threat to millions of people ( $\mathrm{Ng}$ et al. 2003; Liao et al. 2008; Phan et al. 2010). Today, arsenic removal is regarded as one of the most serious issues related to public health. The World Health Organization (WHO) and the Ministry of Health of Arab republic of Egypt have lowered their regulatory values for total As concentration in drinking water to $10 \mu \mathrm{g} \mathrm{L}^{-1}$.

Arsenic is naturally found in rocks and minerals. Arsenic is the 20th most abundant element in the earth's crust at levels of about 2 ppm (Duker et al. 2005). Due to weathering and erosion of rocks and soils and volcanic emissions, arsenic is in contact with the groundwater and creates pollution. In groundwater, arsenic is typically present in one of two oxidation states: arsenite As(III) and arsenate $\mathrm{As}(\mathrm{V})$, with the latter form dominant under oxidizing conditions. Apart from natural sources, arsenic contamination is also due to anthropogenic activities like arsenic pesticides, mining, industrial chemical waste and burning of fossil fuels. Industrially, arsenic is mainly used as a wood preservative, and hence, it has been used in dyes, paints and pigmenting substances. The wastewater from some industrial sources such as gold, copper and zinc ore extraction, acid mine drainage and wood product preservation contain up to $130 \mathrm{mg} \mathrm{L}^{-1}$ soluble arsenic (Hansen et al. 2006; Mohan and Pittman 2007). It is also used in glassmaking, electronics manufacturing and leather tanning industries (Goswami et al. 2012). A small amount of arsenic is used in both human and animal medications and 
care products, and it is present in many food supplement products also (Bundschuh et al. 2012). Hence, long-term exposure to inorganic arsenic compounds can lead to various diseases such as conjunctivitis, hyperkeratosis, hyperpigmentation, cardiovascular diseases, disorders of the central nervous system and peripheral vascular system, skin cancer and gangrene of the limbs (Ghosh et al. 2007). Thus, treatment of arsenic-contaminated water is necessary before intake.

It is important to develop technologies available for As $(\mathrm{V})$ removal. Generally, these technologies should be cost-effective, highly efficient and easy to handle. Additionally, it is expected that the technology should avoid the water quality deterioration, even in the case of improper operation by a local operator who is not well trained. Existing techniques for $\mathrm{As}(\mathrm{V})$ removal include oxidation/ precipitation, coagulation/coprecipitation, nanofiltration, reverse osmosis, electrodialysis, adsorption, ion exchange, foam flotation, solvent extraction and bioremediation (Jain and Singh 2012). These well-established approaches have been adapted for $\mathrm{As}(\mathrm{V})$ removal and have their respective advantages and certain inherent limitations that include the generation of toxic waste, low arsenic removal efficiency and high cost (Guan et al. 2012). Adsorption is one of the most effective methods for As(V) removal, and myriad materials including lanthanum/iron compounds, mineral oxides and biological materials have been studied (Onnby et al. 2012). The use of polymeric resins, activated carbon, activated alumina, iron-coated sand, hydrous ferric oxide and natural ores has generated.

Although activated carbon is still the mostly used compound for heavy metal removal from aqueous solutions, there is fervent research activity on alternative sorbents especially polysaccharides that are abundant, renewable and biodegradable (Pontoni and Fabbricino 2012). Among them chitosan plays a prominent role (Elwakeel 2010a; Yamani et al. 2012; Saha and Sarkar 2012). Chitosan is a poly-N-glucosamine species obtained by the deacetylation of chitin, the most abundant amino-polysaccharide existing in the environment (Liu et al. 2012). It is highly hydrophilic and is characterized by a flexible polymer chain and by a large number of hydroxyl and amino groups that represent potential adsorption sites (Elwakeel et al. 2012). Moreover, it can be considered a lowcost sorbent because it requires little processing, is abundant in nature and represents a by-product of fishery industry (Iqbal et al. 2011). Gang et al. have used an impregnation technique with iron for the improvement of arsenate sorption on chitosan beads (Gang et al. 2010). The mechanism involved is often an ion exchange/precipitation between the impregnated metal and arsenate ions (Min and Hering 1998). However, in most cases, the reuse of the adsorbent is difficult to achieve. Thus, the development of new processes allowing recycling of the sorbent is needed. Previously, magnetic chitosan functionalized with tetraethylenepentamine moieties was prepared (Elwakeel et al. 2009). The adsorption behavior of the chelating resin obtained toward $\mathrm{Mo}(\mathrm{VI})$ in aqueous solution at different experimental conditions was studied. The present work will be directed for the removal of $\mathrm{As}(\mathrm{V})$ from aqueous solution using $\mathrm{Mo}(\mathrm{VI})$-loaded magnetic chitosan resin functionalized with tetraethylenepentamine.

To address this objective in this study, we use molybdate ions which have the ability to complex arsenate ions to increase $\mathrm{As}(\mathrm{V})$ adsorption performance of magnetic chitosan functionalized with tetraethylenepentamine. Arsenate can, thus, be eluted from the sorbent selectively by using another complexing agent. In this study $\mathrm{As}(\mathrm{V})$ sorption onto magnetic chitosan modified with tetraethylenepentamine and molybdate oxoanions was investigated, and the adsorption studies of the obtained resin including $\mathrm{pH}$ optimization, determination of sorption isotherms and kinetics were done.

\section{Materials and methods}

\section{Chemicals}

Chitosan with deacetylation degree (DD) of $82.1 \%$, glutaraldehyde and tetraethylenepentamine (TEPA) were Aldrich products, USA. All other chemicals were Prolabo products and were used as received. Sodium arsenate and ammonium heptamolybdate tetrahydrate were used as a source for $\mathrm{As}(\mathrm{V})$ and $\mathrm{Mo}(\mathrm{VI})$ oxoanions, respectively. $\mathrm{FeSO}_{4} \cdot 7 \mathrm{H}_{2} \mathrm{O}$ and $\mathrm{FeCl}_{3} \cdot 6 \mathrm{H}_{2} \mathrm{O}$ were used for preparing magnetite particles as reported earlier using modified Massart method (Qu et al. 1999).

Preparation of modified magnetic chitosan resins

Magnetic chitosan resin was prepared and characterized according to the previously reported method (Elwakeel et al. 2009; Elwakeel 2009) as follows:

1. Preparation of the magnetic chitosan gel Three grams of chitosan was dissolved in $20 \%$ aqueous solution of acetic acid. One gram of magnetite was added to chitosan solution and stirred until the solution became homogenous. Then $2 \mathrm{~mL}$ of glutaraldehyde solution (50\%) was added, and the solution was stirred with heating until gelatinous product was obtained. The gel obtained was washed with distilled water several times and kept for use.

2. Reaction with epichlorohydrine The cross-linked chitosan gel obtained in step (1) was suspended in $70 \mathrm{~mL}$ isopropyl alcohol, and then $7 \mathrm{~mL}$ 
epichlorohydrine $(62.5 \mathrm{mmol})$ dissolved in $100 \mathrm{~mL}$ acetone/water mixture $(1: 1 \mathrm{v} / \mathrm{v})$ was added. The above mixture was stirred for $24 \mathrm{~h}$ at $60{ }^{\circ} \mathrm{C}$. The solid product obtained was filtered off and washed several times with water followed by ethanol.

3. Reaction with tetraethylenepentamine (TEPA) The product obtained in step (2) was suspended in $100 \mathrm{~mL}$ ethanol/water mixture $(1: 1 \mathrm{v} / \mathrm{v})$ and then treated with $5 \mathrm{~mL}$ TEPA. The reaction mixture was stirred at $60{ }^{\circ} \mathrm{C}$ for $12 \mathrm{~h}$. The product obtained was washed with water followed by ethanol. The produced chitosan/pentamine resin was dried in air and referred by $(\mathrm{R})$. The amine content in $\mathrm{R}$ was estimated using volumetric method of $\mathrm{HCl}$ according to the previously reported method (Atia et al. 2005) and was found to be $5.1 \mathrm{mmol} \mathrm{g}^{-1}$, and the surface area was found to be $110 \mathrm{~m}^{2} \mathrm{~g}^{-1}$ using methylene blue adsorption method (Elwakeel 2009).

Molybdate loading procedure

Known amounts of dry chitosan beads were put in contact with known amounts (volume concentration) of ammonium heptamolybdate tetrahydrate at $\mathrm{pH} 3$ at $25^{\circ} \mathrm{C}$ for $3 \mathrm{~h}$. Later on, the residual concentration of $\mathrm{Mo}(\mathrm{VI})$ was determined using mercaptoacetic acid according to Will and Yoe procedure (Will and Yoe 1953).

\section{Preparation of solutions}

A stock solution $\left(2 \times 10^{-2} \mathrm{M}\right)$ of ammonium heptamolybdate tetrahydrate as Mo(IV) was prepared in distilled water. $\mathrm{HCl}(0.5 \mathrm{M})$ and $\mathrm{NaOH}(0.5 \mathrm{M})$ were used to change the acidity of the medium. Orthophosphoric acid $(0.1 \mathrm{M})$ was used for elution $\mathrm{As}(\mathrm{V})$ from the resin. Stock solution of disodium acid arsenate heptahydrate $\left(1 \times 10^{-2}\right.$ M) was prepared in distilled water. The desired concentrations were then obtained by dilution. The concentration of $\mathrm{As}(\mathrm{V})$ was measured using spectrophotometric method (Lenoble et al. 2003). Calibration curve of $\mathrm{As}(\mathrm{V})$ in distilled water was recorded by measuring the absorbance against concentration at $\lambda_{\max }(870 \mathrm{~nm})$, while the residual concentration of Mo(IV) ion was estimated at $420 \mathrm{~nm}$ using mercaptoacetic acid method (Will and Yoe 1953). The measurements were taken on DR/2010 spectrophotometer, HACH, USA. The path cell length is $1.0 \mathrm{~cm}$. All the experiments are conducted in triplicate, and the deviation was less than $0.1 \%$.

Batch experiments for adsorption of $\mathrm{As}(\mathrm{V})$ by $\mathrm{R}-\mathrm{Mo}$

Adsorption of $\mathrm{As}(\mathrm{V})$ under controlled $\mathrm{pH}$ was carried out by placing $0.1 \mathrm{~g}$ of dry R-Mo in a series of flasks each contains
$100 \mathrm{~mL}$ of $5 \times 10^{-3} \mathrm{M}$ of $\mathrm{As}(\mathrm{V})$ solution. The flasks were conditioned on a shaker at $200 \mathrm{rpm}$ and $25{ }^{\circ} \mathrm{C}$. The uptake of $\mathrm{As}(\mathrm{V})$ was calculated by determining the residual concentration of $\mathrm{As}(\mathrm{V})$ following the above method.

The effect of conditioning time on the adsorption of $\mathrm{As}(\mathrm{V})$ by the R-Mo was investigated. In flask containing $100 \mathrm{~mL}$ of $5 \times 10^{-3} \mathrm{M}$ of $\mathrm{As}(\mathrm{V}), 0.1 \mathrm{~g}$ portions of dry R-Mo was placed at $\mathrm{pH} 8.6$ (natural). The contents of the flasks were equilibrated on the shaker at $300 \mathrm{rpm}$ and $30{ }^{\circ} \mathrm{C}$. One milliliter of the solution (free from resin particles) was taken at different time intervals, and the residual concentration of $\mathrm{As}(\mathrm{V})$ was determined.

The effect of initial concentration of $\operatorname{As}(\mathrm{V})$ on the adsorption was carried out by placing $0.1 \mathrm{~g}$ portions of dry R-Mo in a series of flasks each contains $100 \mathrm{~mL}$ of $\mathrm{As}(\mathrm{V})$ with different concentrations at natural $\mathrm{pH}$. The contents of the flasks were equilibrated on the shaker at $200 \mathrm{rpm}$ and at 25,35 and $45{ }^{\circ} \mathrm{C}$ for $30 \mathrm{~min}$. After equilibration, final concentration and final $\mathrm{pH}$ of $\mathrm{As}(\mathrm{V})$ anions for all flasks were measured.

\section{Column method}

Flow experiments were performed in a plastic column (length $10 \mathrm{~cm}$, diameter $1 \mathrm{~cm}$ ). A small piece of glass wool was placed at the bottom of the column, and then a known quantity of the R-Mo under investigation was placed in the column. A known quantity of the resin under investigation was placed in the column to yield the desired bed height. As $(V)$ solution having an initial concentration of $8 \times 10^{-3}$ $\mathrm{M}$ was flowed downward through the column at a desired flow rate. Samples were collected from the outlet of the column at different time intervals and analyzed for As $(V)$ ion concentration. The operation of the column was stopped when the outlet metal ion concentration matches its initial concentration.

\section{Regeneration of the loaded resin}

Regeneration experiments were performed by placing $1.0 \mathrm{~g}$ of R-Mo in the column and then loading with $\mathrm{As}(\mathrm{V})$ at the flow rate $1 \mathrm{~mL} \mathrm{~min}{ }^{-1}$. After reaching the maximum uptake, the resin was washed carefully by flowing distilled water through the column. The resin loaded by $\mathrm{As}(\mathrm{V})$ was then subjected to regeneration using $50 \mathrm{~mL} 0.1 \mathrm{M}$ of orthophosphoric acid. The resin was then carefully washed with distilled water to become ready for the second run of loading with $\mathrm{As}(\mathrm{V})$. The regeneration efficiency was calculated according to the following equation:

Regeneration effeciency $(\%)=\frac{\text { Uptake in the second run }}{\text { Uptake in the first run }} \times 100$. 


\section{Results and discussion}

\section{Adsorption of Mo(VI) on chitosan-TEPA resin}

Previous studies have shown that the optimum $\mathrm{pH}$ for molybdenum sorption is around 3 (Elwakeel et al. 2009) due to a favorable electrostatic balance between the cationic charge of the protonated functions of chitosan and the high anionic charges of polynuclear hydrolyzed Mo(VI) species. The adsorption isotherm of Mo(VI) by chitosanTEPA resin is a monolayer type. The maximum uptake at plateau and at pH 3 is $8 \mathrm{mmol} \mathrm{g}^{-1}$ (Elwakeel et al. 2009).

\section{Adsorption of $\mathrm{As}(\mathrm{V})$ on R-Mo}

\section{Effect of the loaded amount of Mo(VI)}

The uptake of As(V) by R-Mo shows a straight-line relationship with the amount of Mo(VI) loaded on the resin (Fig. 1a). Obviously, as the amount of loaded Mo(VI) increases, the adsorption of As(V) linearly increases. The percentage of $\mathrm{Mo}(\mathrm{VI})$ released from the adsorbent increases with increasing amount of $\mathrm{Mo}(\mathrm{VI})$ loaded on the resin surface (Fig. 1b). Increasing amount of loaded Mo(VI) involves a decrease in the residual $\mathrm{As}(\mathrm{V})$ concentration. The weakly bound fraction of $\mathrm{Mo}(\mathrm{VI})$ is, thus, less attracted by residual $\mathrm{As}(\mathrm{V})$ in solution, and the release of $\mathrm{Mo}(\mathrm{VI})$ is decreased. Mo(VI) stability on the beads is, thus, improved by high amount of Mo(VI) loaded on the resin. Arsenate ions at $\mathrm{pH}$ ranging between 3 and 4 mainly occur as $\mathrm{H}_{3} \mathrm{AsO}_{4}$ and $\mathrm{H}_{2} \mathrm{AsO}_{4}$ (Couture and Cappellen 2011; Lorenzen et al. 1995). According to the speciation diagram for $\mathrm{As}(\mathrm{V})$ and the stability constants from Jekel (Jekel 1994), the predominant arsenate species is $\mathrm{H}_{2} \mathrm{AsO}_{4}$ between $\mathrm{pH} 3$ and 4 . The mechanism involved in arsenate removal by R-Mo may consist of one or a combination of several reactions including electrostatic attraction, precipitation on Mo(VI) ions and/or ion exchange. However, molybdate is known to form several complexes in acidic media with As(V), P(V), $\mathrm{Si}(\mathrm{V})$ and $\mathrm{Ge}(\mathrm{IV})$ (Farnet et al. 2010). So arsenate sorption is likely to occur through the formation of the arsenomolybdate complex with Mo(VI) ions sorbed on R-Mo resin.

\section{Effect of $p H$}

The $\mathrm{pH}$ may influence the fractional species distribution of $\mathrm{As}(\mathrm{V})$ and the surface properties of the adsorbent, which in turn controls the interactions between adsorbate and adsorbent. To evaluate the effect of $\mathrm{pH}$ on the $\mathrm{As}(\mathrm{V})$ uptake, batch adsorption experiments were performed at different initial $\mathrm{pH}$ values ranging from 1 to 10 . The obtained results shown in Fig. 2a illustrate that the adsorption of $\mathrm{As}(\mathrm{V})$ by R-Mo
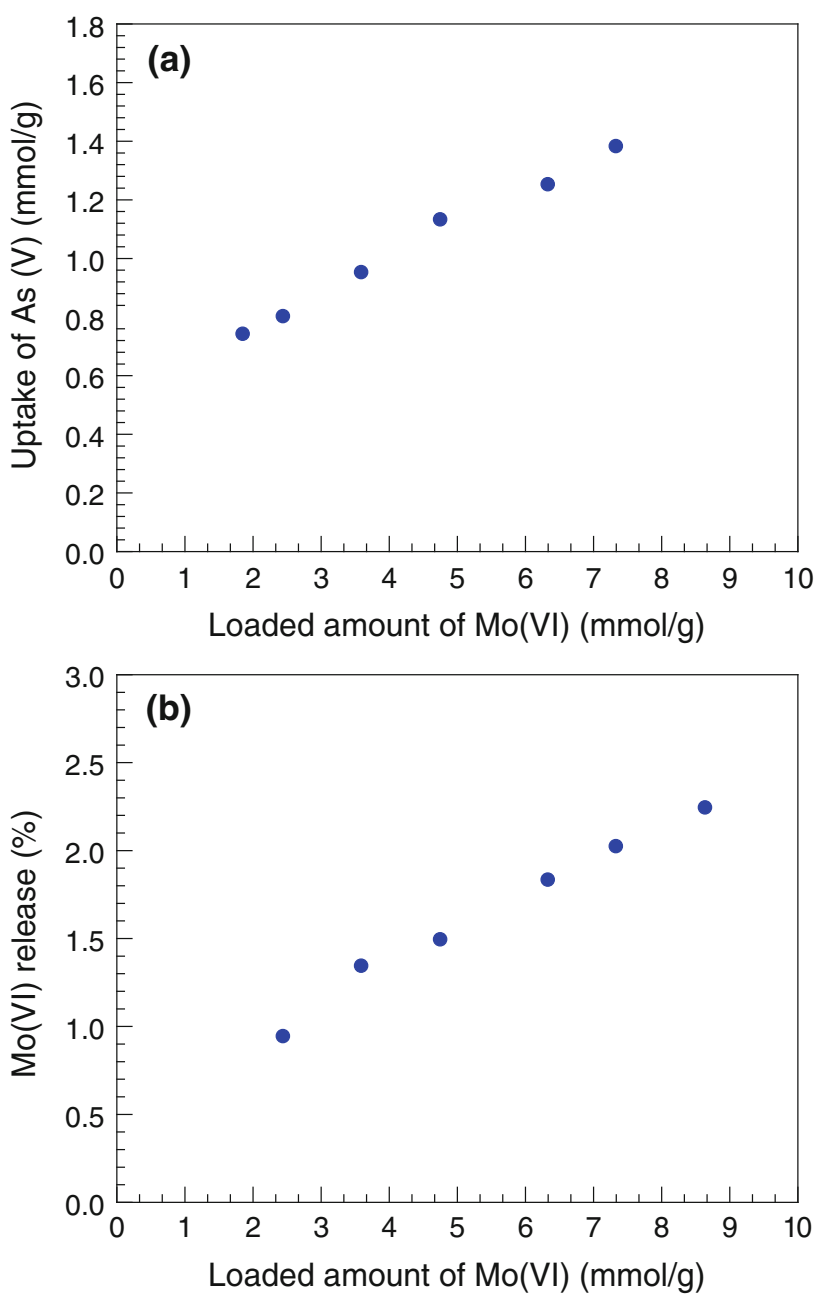

Fig. 1 a Effect of adsorbed amount of Mo(VI) by R-Mo resin on the adsorption of $\mathrm{As}(\mathrm{V}), \mathbf{b} \mathrm{Mo}(\mathrm{VI})$ release $(\%)$ to the medium after $\mathrm{As}(\mathrm{V})$ adsorption

resin is strongly $\mathrm{pH}$ dependent. The maximum sorption of As $(\mathrm{V})$ is observed in the $\mathrm{pH}$ from 2.5 to 3.5 , and at extremely acid situation, it decreases with a further increase in $\mathrm{pH}$. The observed decrease in the uptake value with increasing $\mathrm{pH}$ may be attributed to the formation of arsenate species with relative lower ability for interaction with $\mathrm{Mo}(\mathrm{VI})$ loaded on the resin along with the high desorption of $\mathrm{Mo}(\mathrm{VI})$ from the resin as shown in Fig. 2b. It is worth to mention that Mo(VI) release percentage at $\mathrm{pH}$ around 2 is lowest; this result indicates that $\mathrm{pH}$ from 2 to 3 is optimum for $\mathrm{As}(\mathrm{V})$ removal by R-Mo resin. Also, it was observed that the equilibrium (final) $\mathrm{pH}$ is higher than the initial $\mathrm{pH}$ (Fig. 2c).

\section{Kinetics}

To design an appropriate adsorption treatment process, it is important to understand the rate at which pollutant is removed. Therefore, the study on adsorption kinetics is 

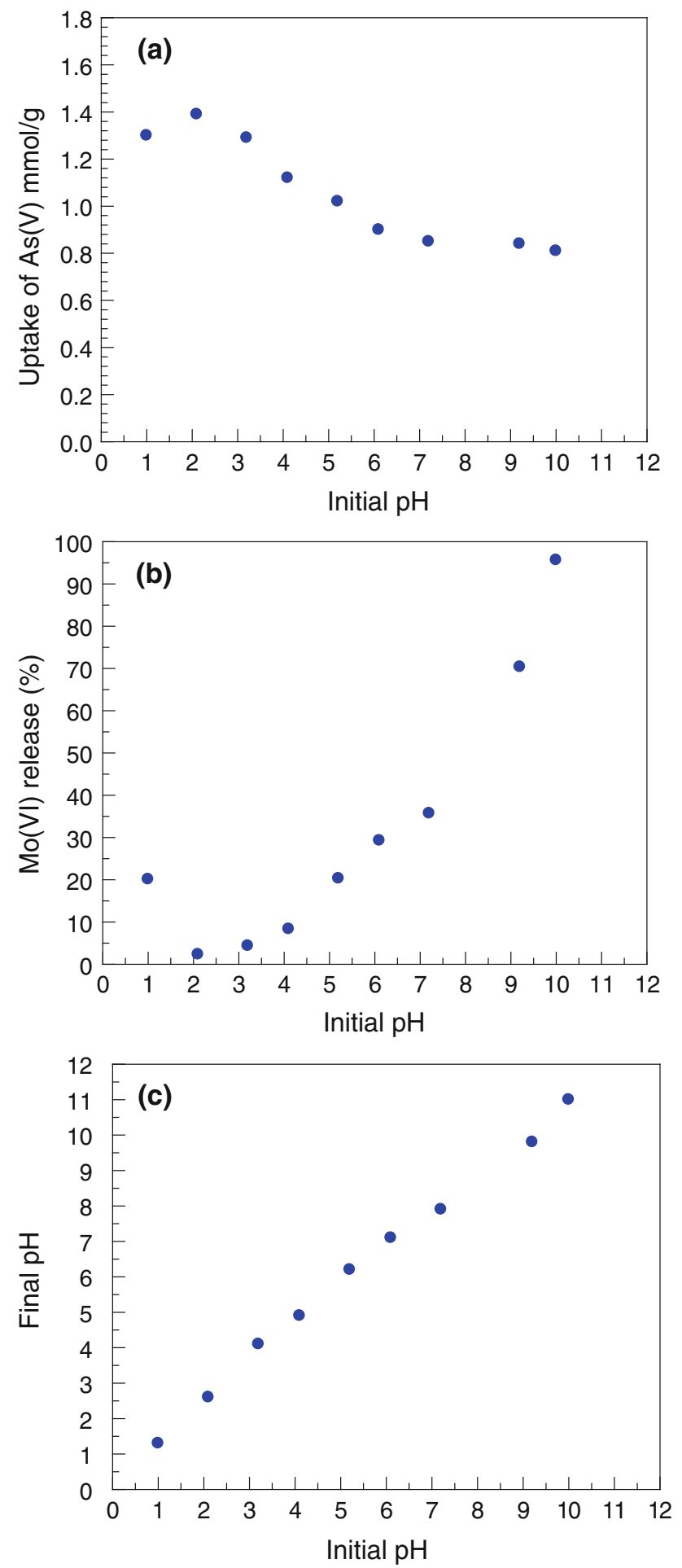

Fig. 2 a Effect of $\mathrm{pH}$ on the adsorption of $\mathrm{As}(\mathrm{V})$ on R-Mo resin at $25^{\circ} \mathrm{C}$ and initial concentration of $5 \times 10^{-3}, \mathbf{b} \mathrm{Mo}(\mathrm{VI})$ release $(\%)$ to the medium after $\mathrm{As}(\mathrm{V})$ adsorption at different $\mathrm{pH}$ values, $\mathbf{c}$ the recorded equilibrium $\mathrm{pH}$ (final $\mathrm{pH}$ )

crucial, as it describes the solute uptake rate which in turn controls the residence time of adsorbate uptake at the solid-solution interface. The rate of uptake of $\mathrm{As}(\mathrm{V})$ on
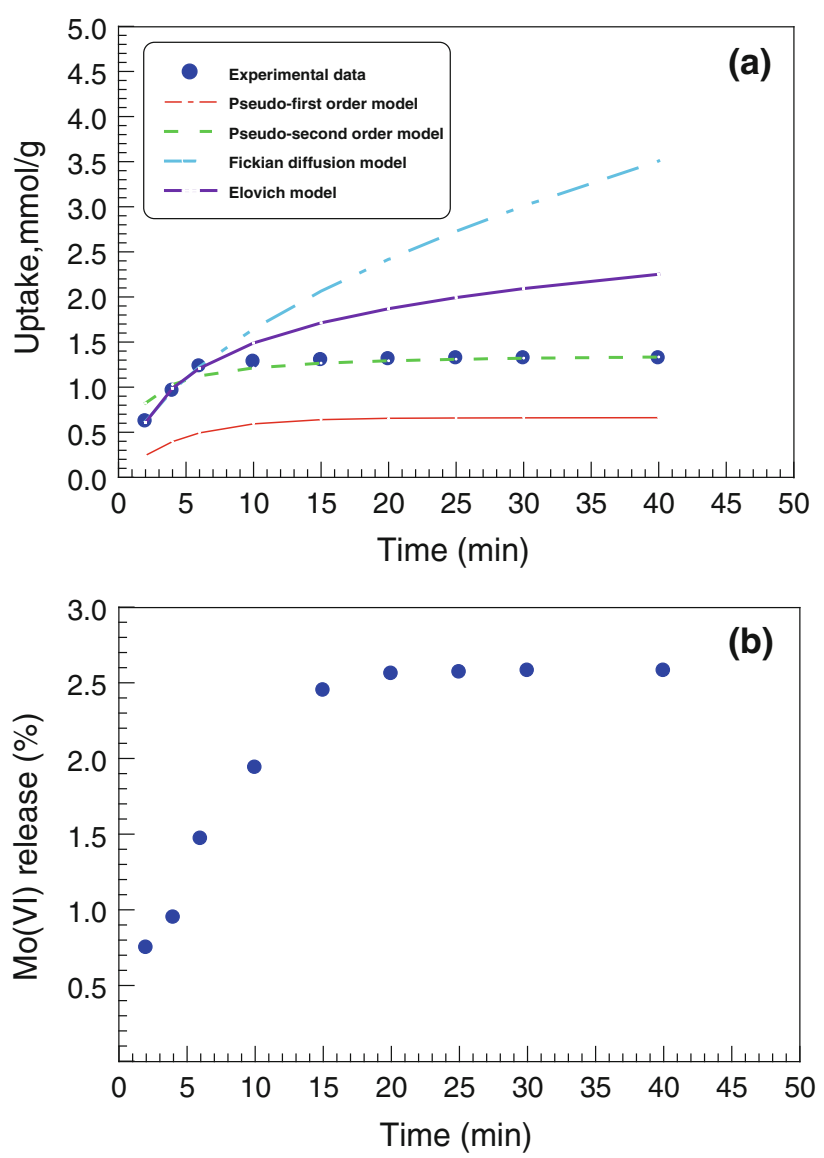

Fig. 3 a Effect of time on the uptake of $\mathrm{As}(\mathrm{V})$ by R-Mo resin at $25^{\circ} \mathrm{C}, \mathrm{pH} 2$, initial concentration of $5 \times 10^{-3} \mathrm{M}, \mathbf{b} \mathrm{Mo}(\mathrm{VI})$ release $(\%)$ to the medium after $\mathrm{As}(\mathrm{V})$ adsorption at different time intervals

used adsorbent is rapid in the beginning, and $93.2 \%$ adsorption is completed in $6 \mathrm{~min}$ and becomes constant after $20 \mathrm{~min}$, which indicates that equilibrium has been achieved (Fig. 3a). These results indicated a rapid initial uptake rate of $\mathrm{As}(\mathrm{V})$, followed by a slower removal that gradually approaches an equilibrium condition. About $100 \%$ removal of arsenate was achieved within the first 20 min of contact. This fast rate of adsorption makes this resin promising for practical applications in comparison with other reported adsorbents. The equilibrium time of some previously studied resins extends from $2 \mathrm{~h}$ up to few days (Navarro and Alguacil 2002; Miller and Zimmerman 2010; Goswami et al. 2012).

Figure $3 \mathrm{~b}$ shows rate of $\mathrm{Mo}(\mathrm{V})$ release to the solution; it could be seen that $1.47 \%$ of the loaded $\mathrm{Mo}(\mathrm{VI})$ is released after $6 \mathrm{~min}$ and $\mathrm{Mo}(\mathrm{V})$ release becomes constant after $20 \mathrm{~min}(2.56 \%)$. The obtained data indicate that $6 \mathrm{~min}$ is the optimum adsorption time for removal of $\mathrm{As}(\mathrm{V})$ by the studied resin.

To better understand the adsorption kinetics of $\mathrm{As}(\mathrm{V})$, pseudo-first-order and pseudo-second-order models were used to simulate the adsorption process. The models are 
expressed as follows: (1) Pseudo-first-order model (Lagergren 1898):

$q_{\mathrm{t}}=q_{\mathrm{e}}\left[1-\exp ^{-k_{1} t}\right]$

Its linearized equation is shown below:

$\log \left(q_{\mathrm{e}}-q_{\mathrm{t}}\right)=\log q_{\mathrm{e}}-\left(\frac{k_{1}}{2.303}\right) t$

where $k_{1}$ is the pseudo-first-order rate constant $\left(\mathrm{min}^{-1}\right)$ of adsorption and $q_{\mathrm{e}}$ and $q_{\mathrm{t}}\left(\mathrm{mmol} \mathrm{g}^{-1}\right)$ are the amounts of $\mathrm{As}(\mathrm{V})$ adsorbed at equilibrium and time t, respectively. (2) Pseudo-second-order model (Ho and McKay 1999):

$q_{\mathrm{t}}=\frac{k_{2} t}{1+k_{2} q_{\mathrm{e}} t}$

Its linearized equation is shown below:

$\frac{t}{q_{\mathrm{t}}}=\frac{1}{k_{2} q_{\mathrm{e}}^{2}}+\left(\frac{1}{q_{\mathrm{e}}}\right) t$

where $k_{2}$ is the pseudo-second-order rate constant of adsorption $\left(\mathrm{g} \mathrm{mmol}^{-1} \mathrm{~min}^{-1}\right)$. The kinetic parameters in both models are determined from the linear plots of $\log$ $\left(q_{\mathrm{e}}-q_{\mathrm{t}}\right)$ versus $t$ for pseudo-first-order model or $\left(t / q_{\mathrm{t}}\right)$ versus $t$ for pseudo-second-order model. The validity of each model is checked by the fitness of the straight line $\left(R^{2}\right)$ as well as the experimental and calculated values of $q_{\mathrm{e}}$. Accordingly, and as shown in Table 1, according to the reported $R^{2}$, it can be found that the adsorption kinetics data are well described by both pseudo-first-order and pseudo-second-order rate model; however, the value of $q_{\text {e,calc }}$ obtained from pseudo-second-order model (1.38) is highly consistent with experimental $q_{\mathrm{e}}(1.35)$ more than calculated from pseudo-first-order model (0.6603). So pseudo-second-order rate is more valid than pseudo-firstorder one.

The adsorption kinetics study is helpful to understand the mechanism of adsorption reactions. The pseudo-second-order kinetic model is based on the assumption that the rate-limiting step may be chemisorption involving valency forces through sharing or exchange of electrons between sorbent and sorbate (Azizian 2004; Cui et al. 2012), which is suitable for sorptions at low initial concentration. It was found that the kinetic experimental data obtained could be best fitted into the pseudo-second-order rate model. This observation suggests that arsenic adsorption onto R-Mo particles involves chemisorption. This observation confirms that arsenate sorption is likely to occur through the formation of the arsenomolybdate complex on R-Mo resin.

Most adsorption reactions take place through multistep mechanism comprising (1) external film diffusion, (2) intraparticle diffusion and (3) interaction between adsorbate and active site. Since the first step is excluded by shaking the solution, the rate-determining step is one of the other two steps. To know whether the intraparticle diffusion is the rate-determining step or not, the uptake/time data were treated according to Fickian diffusion low (Elwakeel 2010b).

$q_{t}=K_{i} t^{0.5}+X$

where $q_{\mathrm{t}}$ is the amount of $\mathrm{As}(\mathrm{V})$ adsorbed at time $t$ and $K_{i}$ is intraparticle diffusion rate $\left(\mathrm{mmol} \mathrm{g}^{-1} \mathrm{~min}^{-0.5}\right)$. The $K_{i}$ is the slope of straight-line portions of the plot of $q_{\mathrm{t}}$ versus $t^{0.5}$. The plot of qt against $t^{0.5}$ gave two straight-line portions with two different slopes and intercept values (Fig. 4a). The $K_{i}$ value obtained from the slope of the first straight-line portion is $0.588\left(\mathrm{mmol} \mathrm{g}^{-1} \mathrm{~min}^{-0.5}\right)$. This high value of $K_{i}$ indicates the fast transfer. The negative value of $X(-0.214)$ indicates no boundary layer effect on the rate of adsorption. This can be explained on the basis of the formation of arsenomolybdate complex on resin surface.

Elovich equation was also applied to the sorption of $\mathrm{As}(\mathrm{V})$ by the chitosan resins according to the relation (Elwakeel and Rekaby 2011):

$q_{t}=1 / \beta \ln (\alpha \beta)+1 / \beta \ln t$

where $q_{\mathrm{t}}$ is the sorption capacity at time $t$ and $\alpha$ the initial sorption rate $\left(\mathrm{mmol} \mathrm{g}^{-1} \mathrm{~min}^{-1}\right.$ ) and $\beta$ the desorption constant related to the activation energy for chemisorption $\left(\mathrm{g} \mathrm{mmol}^{-1}\right)$. Thus, the constants can be obtained from the slope and intercept of a straight-line plot of $q_{\mathrm{t}}$ versus $\log$ $t$ (Fig. 4b). The linearization of the equation giving the rate of reaction allows obtaining the initial sorption rate, $\alpha$ $\left(\mathrm{mmol} \mathrm{g}{ }^{-1} \mathrm{~min}^{-1}\right.$ ), from the intercept of a straight-line plot of $q_{\mathrm{t}}$ versus $\ln t$. The value of $\alpha$ for the adsorption of $\mathrm{As}(\mathrm{V})$ anions on resin R-Mo is $0.833\left(\mathrm{mmol} \mathrm{g}^{-1} \mathrm{~min}^{-1}\right)$.

Table 1 Kinetic parameters of the adsorption of $\mathrm{As}(\mathrm{V})$ on the studied resin

\begin{tabular}{|c|c|c|c|c|c|c|c|c|c|c|c|}
\hline \multicolumn{3}{|c|}{ Pseudo-first-order } & \multicolumn{3}{|c|}{ Pseudo-second-order } & \multicolumn{3}{|l|}{ Fickian diffusion low } & \multicolumn{3}{|c|}{ Elovich equation } \\
\hline $\begin{array}{l}k_{1} \\
\left(\min ^{-1}\right)\end{array}$ & $\begin{array}{l}q_{\mathrm{e}, \text { calc }} \\
\left(\mathrm{mmol} \mathrm{g}^{-1}\right)\end{array}$ & $R^{2}$ & $\begin{array}{l}k_{2} \\
\left(\mathrm{~g} \mathrm{mmol}^{-1} \mathrm{~min}\right)\end{array}$ & $\begin{array}{l}q_{\mathrm{e}, \text { calc }} \\
\left(\mathrm{mmol} \mathrm{g}^{-1}\right)\end{array}$ & $R^{2}$ & $\begin{array}{l}K_{\mathrm{i}} \\
\left(\mathrm{mmol} \mathrm{g}^{-1} \min ^{-0.5}\right)\end{array}$ & $X$ & $R^{2}$ & $\begin{array}{l}\alpha(\mathrm{mmol} \mathrm{g} \\
\left.\min ^{-1}\right)\end{array}$ & $\begin{array}{l}\beta \\
\left(\mathrm{g} \mathrm{mmol}^{-1}\right)\end{array}$ & $R^{2}$ \\
\hline 0.2286 & 0.6603 & 0.9985 & 0.5323 & 1.3817 & 0.9980 & 0.5887 & -0.2141 & 0.9999 & 0.8327 & 1.8238 & 0.9929 \\
\hline
\end{tabular}



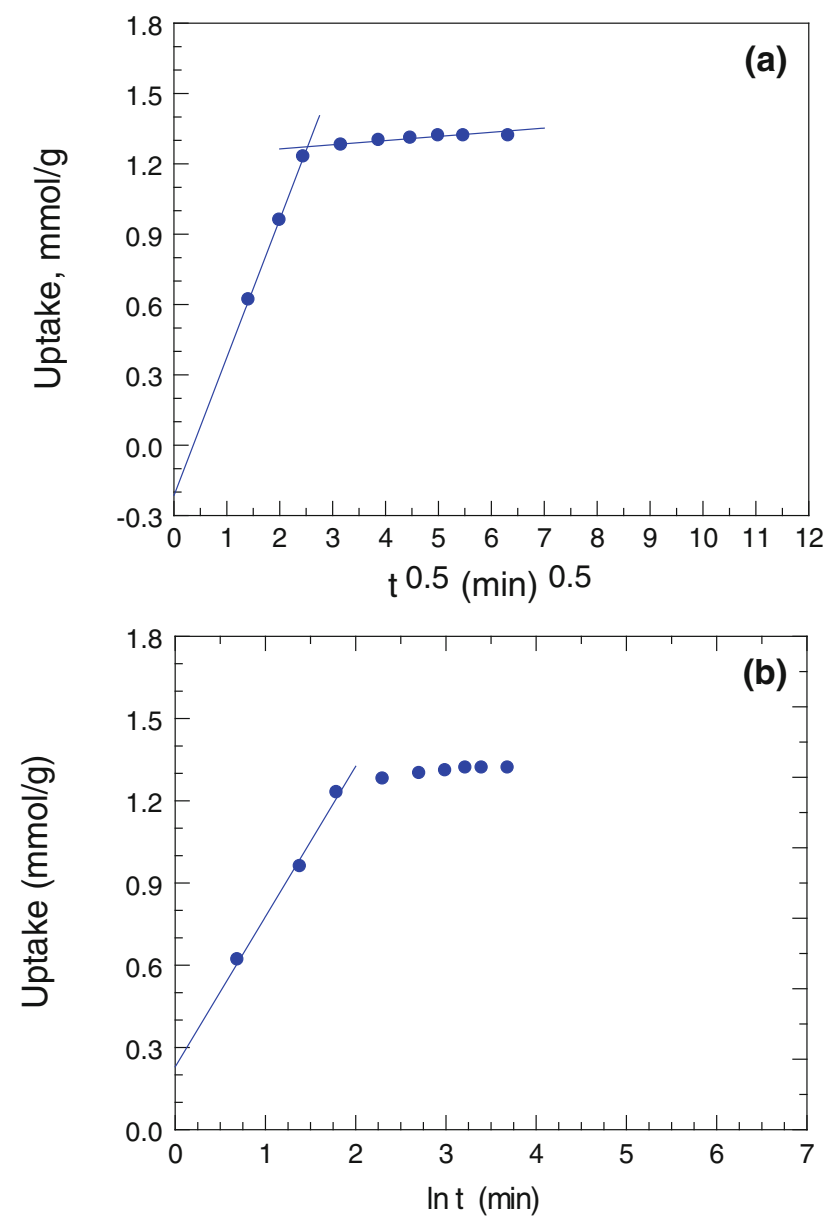

Fig. 4 a Intraparticle diffusion and $\mathbf{b}$ Elovich kinetics of $\mathrm{As}(\mathrm{V})$ uptake by $\mathrm{R}-\mathrm{Mo}$ resin at $25^{\circ} \mathrm{C}, \mathrm{pH} 2$, initial concentration of $5 \times 10^{-3} \mathrm{M}$

This value indicates that the initial sorption rate of R-Mo is the high compared with other studies, which may be attributed to the high concentration of $\mathrm{Mo}(\mathrm{V})$ on R-Mo surface allowed for reacting with $\mathrm{As}(\mathrm{V})$ ions. The value of $\beta$ (desorption constant) is found to be $1.82 \mathrm{~g} \mathrm{mmol}^{-1}$; this value is small compared with other studies, which indicates the low activation energy required for chemisorption and consequently the high affinity of the studied resin toward As(V) ions. The data obtained indicate that the studied resin is promising for $\mathrm{As}(\mathrm{V})$ removal relative to the previously reported ones (Jain and Singh 2012; Cui et al. 2012; Mel'nik et al. 2012).

\section{Equilibrium adsorption isotherm}

Study on $\mathrm{As}(\mathrm{V})$ adsorption isotherm was conducted at $\mathrm{pH}$ $2.0 \pm 0.1$, the optimal $\mathrm{pH}$ for $\mathrm{As}(\mathrm{V})$ adsorption on the sorbent (Fig. 5a). Obviously, increasing the As(V) concentration involves an increase in the uptake of $\mathrm{As}(\mathrm{V})$. The percentage of $\mathrm{Mo}(\mathrm{VI})$ released from the resin increases
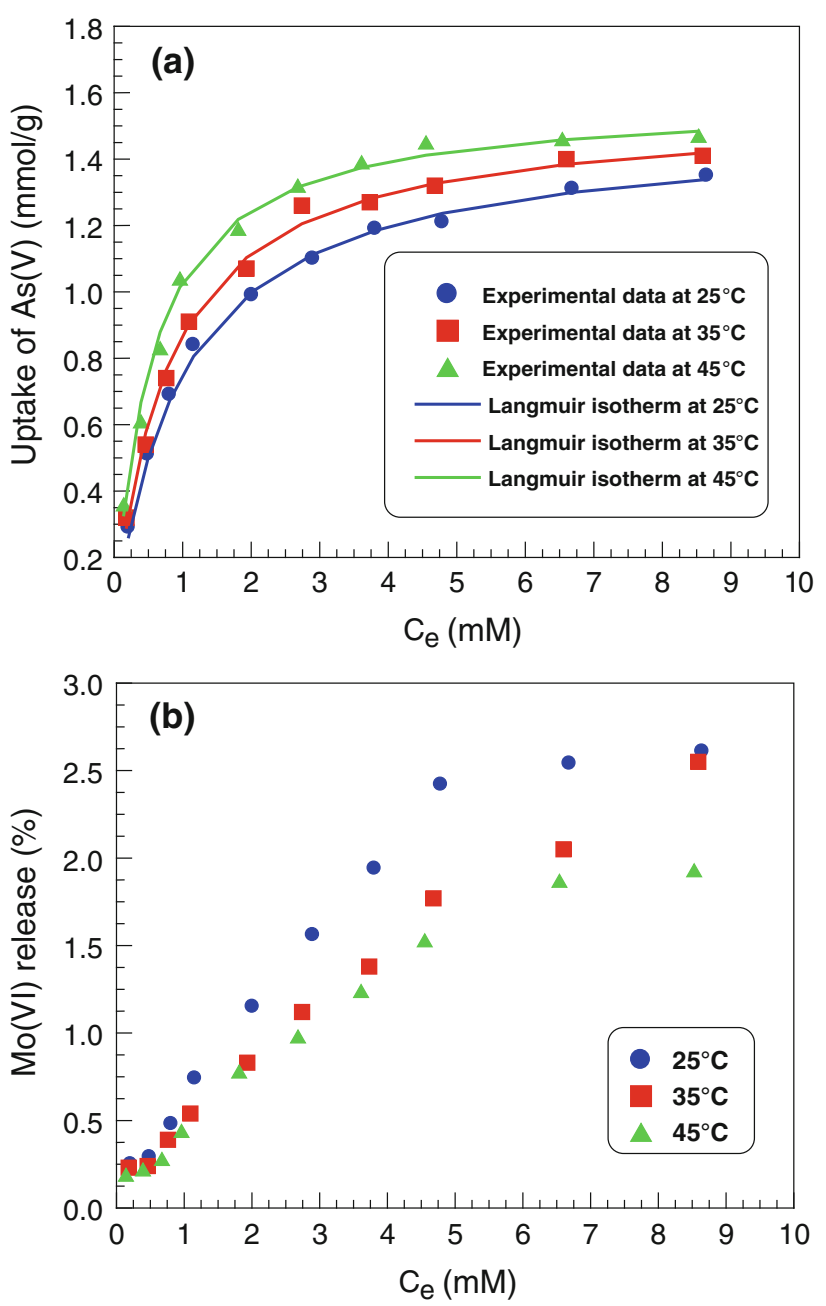

Fig. 5 a Nonlinear Langmuir isotherms for the adsorption of $\mathrm{As}(\mathrm{V})$ ions by $\mathrm{R}-\mathrm{Mo}$ resin at different temperatures and $\mathrm{pH} 2$, b $\mathrm{Mo}(\mathrm{VI})$ release $(\%)$ to the medium after $\mathrm{As}(\mathrm{V})$ adsorption at different equilibrium concentrations

with increasing As(V) concentration (Fig. 5b). This trend may be explained by the coexistence of two kinds of Mo(VI) in the resin: A part of the Mo(VI) which has been adsorbed is tightly bound to the resin network, while another part of the Mo(VI) is weakly bound to the resin, the latter being readily desorbed from the resin while the former is more stable. Increasing the amount of $\mathrm{As}(\mathrm{V})$ in the solution may result in the attraction of the proportion of the labile Mo(VI) which is easily released to the solution where it may be complexed with arsenate ions: Arsenomolybdate complex is then adsorbed with more difficulty on the resin, and the Mo(VI) release percentage increases. $\mathrm{Mo}(\mathrm{VI})$ release is usually lower than $2.42 \%$ at $30-\mathrm{min}$ equilibrium time and $25^{\circ} \mathrm{C}$, with the exception of the higher As(V) residual concentrations; it was observed that $\mathrm{Mo}(\mathrm{VI})$ release decreases with increasing temperature, while As(V) uptake increases with increasing temperature. 
Both Langmuir and Freundlich isotherm models were used to describe the relationship between the amount of $\mathrm{As}(\mathrm{V})$ adsorbed and its equilibrium concentration in aqueous solution. Langmuir model is applicable to homogeneous sorption, in which the adsorption of each adsorbate molecule onto the sorbent has equal adsorption activation energy. Langmuir model can be expressed by the following equation (Langmuir 1918):

$q_{\mathrm{e}}=\frac{Q_{\max } K_{L} C_{\mathrm{e}}}{1+K_{L} C_{\mathrm{e}}}$

where $q_{\mathrm{e}}$ is the adsorbed value of $\mathrm{As}(\mathrm{V})$ at equilibrium concentration $\left(\mathrm{mmol} \mathrm{g}^{-1}\right), Q_{\max }$ is the maximum adsorption capacity $\left(\mathrm{mmol} \mathrm{g}^{-1}\right), K_{L}$ is the Langmuir binding constant which is related to the energy of adsorption $\left(\mathrm{L} \mathrm{mmol}{ }^{-1}\right.$ ), and $C_{\mathrm{e}}$ is the equilibrium concentration of $\mathrm{As}(\mathrm{V})$ in solution $\left(\mathrm{mmol} \mathrm{L}^{-1}\right)$.

Its linearized equation is shown below:

$\frac{C_{\mathrm{e}}}{q_{\mathrm{e}}}=\frac{C_{\mathrm{e}}}{Q_{\max }}+\frac{1}{K_{L} Q_{\max }}$

The most important multisided adsorption isotherm for heterogeneous surfaces is the Freundlich isotherm, characterized by the heterogeneity factor $1 / n$. The Freundlich model is described by Freundlich (1906):

$q_{\mathrm{e}}=K_{F} C_{\mathrm{e}}^{1 / n}$

where $K_{F}$ and $n$ are the Freundlich constants related to the adsorption capacity and intensity, respectively.Its linearized expression is shown below:

$\log q_{\mathrm{e}}=\log K_{\mathrm{F}}-\frac{1}{n} \log C_{\mathrm{e}}$

The values of $K_{L}, Q_{\max }, K_{F}$ and $n$ at different temperatures are reported in Table 2 . The maximum adsorption capacities $\left(Q_{\max }\right)$ obtained at different temperatures are in good agreement with the experimental ones, and the values of $R^{2}$ reported in Table 2, which is a measure of the goodness of fit, confirm the better representation of the experimental data by Langmuir model than by Freundlich model. This indicates the homogeneity of active sites on the resin surface. The observed increase in both $Q_{\max }$ and $K_{L}$ with increasing temperature may be related to the increase in the stability of the complex formed between arsenate and molybdate anions.

The degree of suitability of the obtained resins toward $\mathrm{As}(\mathrm{V})$ was estimated from the values of the separation factor $\left(R_{L}\right)$ using the following relation (Qi and Xu 2004):

$R_{\mathrm{L}}=\frac{1}{1+K_{L} \mathrm{C}_{\mathrm{o}}}$

where $K_{L}$ is the Langmuir equilibrium constant and $C_{o}$ is the initial concentration of $\mathrm{As}(\mathrm{V})$. Values of $0<R_{L}<1$ indicate the suitability of the process. The values of $R_{L}$ for the investigated resin toward the adsorption of $\mathrm{As}(\mathrm{V})$ lie between 0.050 and 0.655 for all concentration and temperature ranges. This implies that the adsorption of $\mathrm{As}(\mathrm{V})$ on R-Mo resin from aqueous solution is favorable under the conditions used in this study.

The values of $K_{L}$ at different temperatures were processed according to the following van't Hoff equation (Atia et al. 2008) to obtain the thermodynamic parameters of the adsorption process:

$\ln K_{\mathrm{L}}=\frac{-\Delta H^{\circ}}{R T}+\frac{\Delta S^{\circ}}{R}$

where $\Delta H^{\circ}$ and $\Delta S^{\circ}$ are enthalpy and entropy changes, respectively, $R$ is the universal gas constant (8.314 $\mathrm{J} \mathrm{mol}^{-1} \mathrm{~K}$ ), and $T$ is the absolute temperature (in Kelvin). The values of $\Delta H^{\circ}$ and $\Delta S^{\circ}$ were calculated and reported in Table 3. The positive values of $\Delta H^{\circ}$ indicate the endothermic nature of adsorption process. The values of enthalpy obtained are coherent with chemical process, which confirms the complex formation between arsenate and molybdate anions on the resin surface. The small positive values of $\Delta S^{\circ}$ suggest the slight increase in randomness during the adsorption of $\mathrm{As}(\mathrm{V})$. The source of this small entropy gain may be due to liberation of water

Table 3 Enthalpy, entropy and free energy changes for the adsorption of $\mathrm{As}(\mathrm{V})$ on the studied resin

\begin{tabular}{lllll}
\hline$\Delta H^{\circ}\left(\mathrm{kJ} \mathrm{mol}^{-1}\right)$ & $\Delta S^{\circ}\left(\mathrm{J} \mathrm{mol}^{-1} \mathrm{~K}\right)$ & \multicolumn{4}{l}{$\Delta G^{\circ}\left(\mathrm{kJ} \mathrm{mol}^{-1}\right)$} \\
\cline { 3 - 5 } & & $298 \mathrm{~K}$ & $308 \mathrm{~K}$ & $318 \mathrm{~K}$ \\
\hline 22.6732 & 0.0762 & -0.0519 & -0.8145 & -1.5771 \\
\hline
\end{tabular}

Table 2 Langmuir and Freundlich constants for the adsorption of $\mathrm{As}(\mathrm{V})$ on the studied resin

\begin{tabular}{|c|c|c|c|c|c|c|c|}
\hline \multirow[t]{2}{*}{ Temperature $\left({ }^{\circ} \mathrm{C}\right)$} & \multicolumn{4}{|l|}{ Langmuir constants } & \multicolumn{3}{|c|}{ Freundlich constants } \\
\hline & $Q_{\max , \exp }\left(\mathrm{mmol} \mathrm{g}^{-1}\right)$ & $Q_{\max , \text { calc }}\left(\mathrm{mmol} \mathrm{g}^{-1}\right)$ & $K_{L}\left(\mathrm{~L} \mathrm{mmol}^{-1}\right)$ & $R^{2}$ & $n$ & $K_{f}$ & $R^{2}$ \\
\hline 25 & 1.35 & 1.4866 & 1.0544 & 0.9993 & 1.7956 & 0.7328 & 0.9802 \\
\hline 35 & 1.41 & 1.5471 & 1.2864 & 0.9991 & 2.0848 & 0.8194 & 0.9645 \\
\hline 45 & 1.47 & 1.5766 & 1.8789 & 0.9993 & 2.0482 & 0.9716 & 0.9804 \\
\hline
\end{tabular}


molecules from the hydrated shells of the sorbed species (Atia et al. 2008). Gibbs free energy of adsorption $\left(\Delta G^{\circ}\right)$ was calculated from the following relation and given in Table 3:

$\Delta G^{\circ}=\Delta H^{\circ}-T \Delta S^{\circ}$

The negative values of $\Delta G^{\circ}$ obtained indicate that the adsorption reaction is spontaneous. The observed increase in negative values of $\Delta G^{\circ}$ with increasing temperature may be attributed to the endothermic nature of the reaction between resin active sites and $\mathrm{As}(\mathrm{V})$ anions. This may also be reflected in the values of $K_{L}$. The values of $K_{L}$ increase as the temperature increases, indicating higher affinity of the resin toward $\mathrm{As}(\mathrm{V})$ at higher temperature.

\section{Column studies}

\section{Effect of flow rate}

The breakthrough curves of the resin toward $\mathrm{As}(\mathrm{V})$ at different flow rates $\left(2,4\right.$ and $\left.6 \mathrm{~mL} \mathrm{~min}^{-1}\right)$ and a fixed bed height of $2.54 \mathrm{~cm}$ are shown in Fig. 6a. The breakthrough points occurred after $150 \mathrm{~min}$ at flow rate of $2 \mathrm{~mL} \mathrm{~min}^{-1}$. This attributed to the higher efficiency of the resin toward $\mathrm{As}(\mathrm{V})$ anions and makes it promising in the field of water and wastewater treatment. Breakthrough and exhaustion occurred faster at higher flow rates. Also as the flow rate increases, $\mathrm{As}(\mathrm{V})$ concentration in the effluent increases rapidly, resulting in much sharper breakthrough curves. Figure $6 \mathrm{~b}$ shows that about 15,30 and 45 bed volumes of $\mathrm{As}(\mathrm{V})$ solution were treated from arsenic $(\mathrm{C} / \mathrm{C} 0<0.03)$ in $15 \mathrm{~min}$ at flow rates of 2,4 and $6 \mathrm{~mL} \mathrm{~min}^{-1}$, respectively. This indicates that high flow rate $\left(6 \mathrm{~mL} \mathrm{~min}{ }^{-1}\right)$ is more suitable for practical application than lower flow rate.

\section{Effect of bed height}

The effect of bed height was studied at 2.45, 5.09 and $7.64 \mathrm{~cm}$, while the flow rate was held constant at $4 \mathrm{~mL} \min ^{-1}$ (Fig. 7a, b). The data of the effect of bed height of R-Mo resin on the uptake of the $\mathrm{As}(\mathrm{V})$ are reported in Table 4 . The influence of bed height was tested in terms of breakthrough time $\left(t_{\mathrm{b}}\right)$, saturation time $\left(t_{\mathrm{s}}\right)$ and number of treated bed volumes. It was found that changing bed height and column size has minor effect on the number of treated bed volumes (Fig. 7b); this helps us to predict the number of treated bed volumes in case of using huge column in the applied scale. Bed depth service time model (BDST) is a simple model relates bed height $(Z)$ to saturation time $\left(t_{\mathrm{s}}\right)$ of the column through the following Eq. (15) (Balci et al. 2011):
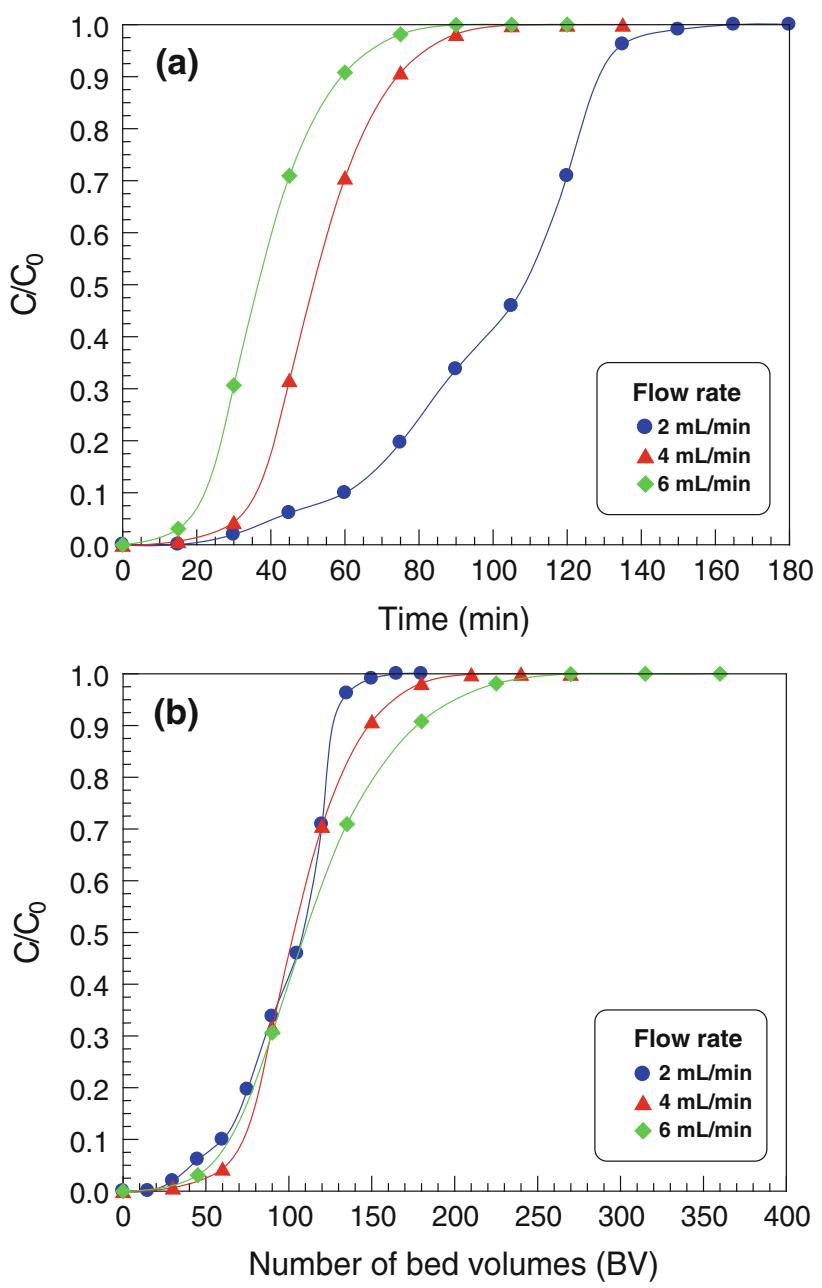

Fig. 6 Effect of flow rate on breakthrough curves for the adsorption of $\mathrm{As}(\mathrm{V})$ ions by R-Mo resin from initial concentration of $8 \times 10^{-3}$ $\mathrm{M}$ and $\mathrm{pH}$ 2: $\mathbf{a}$ as a function of time (min), $\mathbf{b}$ as a function of number of bed volumes (BV)

$t_{s}=\frac{N_{\mathrm{o}} Z}{C_{\mathrm{o}} v}-\frac{1}{K_{\mathrm{a}} C_{\mathrm{o}}} \ln \left(\frac{C_{\mathrm{o}}}{C_{\mathrm{t}}}-1\right)$

where $C_{\mathrm{t}}\left(\mathrm{mmol} \mathrm{L}^{-1}\right)$ is the concentration of metal ion at the saturation time (i.e., $\left.C_{\mathrm{o}} / C_{\mathrm{t}}=100 / 99\right), C_{\mathrm{o}}\left(\mathrm{mmol} \mathrm{L}^{-1}\right)$ is the initial concentration, $N_{\mathrm{o}}$ is the total sorption capacity (mmol of adsorbate/ $\mathrm{L}$ of adsorbent), $v$ is the linear velocity $\left(\mathrm{cm} \mathrm{min}{ }^{-1}\right)$, and $K_{\mathrm{a}}$ is the rate constant of adsorption ( $\left.\mathrm{L} \mathrm{mmol}{ }^{-1} \mathrm{~min}\right)$. The values of $N_{\mathrm{o}}$ and $K_{\mathrm{a}}$ were calculated from the slope and intercept of the BDST plot. The calculated value of $N_{\mathrm{o}}$ was found to be comparable with the experimental values of $Q_{\max }$. This indicates the validity of the BDST model for the investigated resin. If $K_{\mathrm{a}}$ is large, even a short resin bed will avoid the breakthrough limit. In case of small values of $K_{\mathrm{a}}$, a progressively longer bed would be required to delay the breakthrough point. The value of $K_{\mathrm{a}}$ for resin is $0.0097\left(\mathrm{~L} \mathrm{mmol}^{-1} \mathrm{~min}\right)$. The 

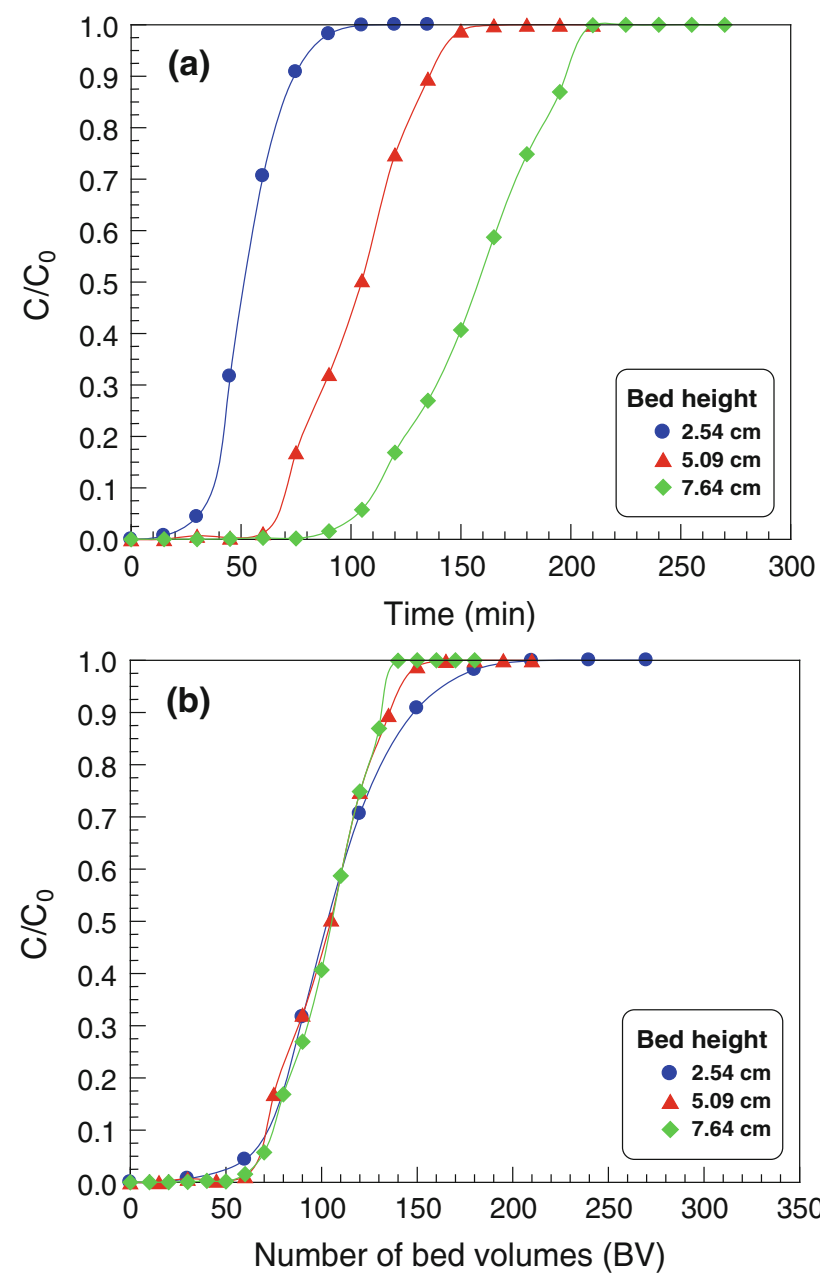

Fig. 7 Effect of bed height on breakthrough curves for the adsorption of $\mathrm{As}(\mathrm{V})$ ions by R-Mo resin from initial concentration of $8 \times 10^{-3}$ $\mathrm{M}$ and $\mathrm{pH} 2$ : $\mathbf{a}$ as a function of time (min), $\mathbf{b}$ as a function of number of bed volumes (BV)

critical bed height $\left(Z_{\mathrm{o}}\right)$ can be calculated by setting $t_{\mathrm{s}}=0$ in Eq. (15) and rearranging to get

$Z_{\mathrm{o}}=\frac{v}{K_{\mathrm{a}} N_{\mathrm{o}}} \ln \left(\frac{C_{\mathrm{o}}}{C_{\mathrm{b}}}-1\right)$

where $C_{\mathrm{b}}$ is the breakthrough metal ion concentration $\left(\mathrm{mmol} \mathrm{L}{ }^{-1}\right)$. The above equation implies that $Z_{\mathrm{o}}$ depends on the kinetics of the sorption process, the residence time

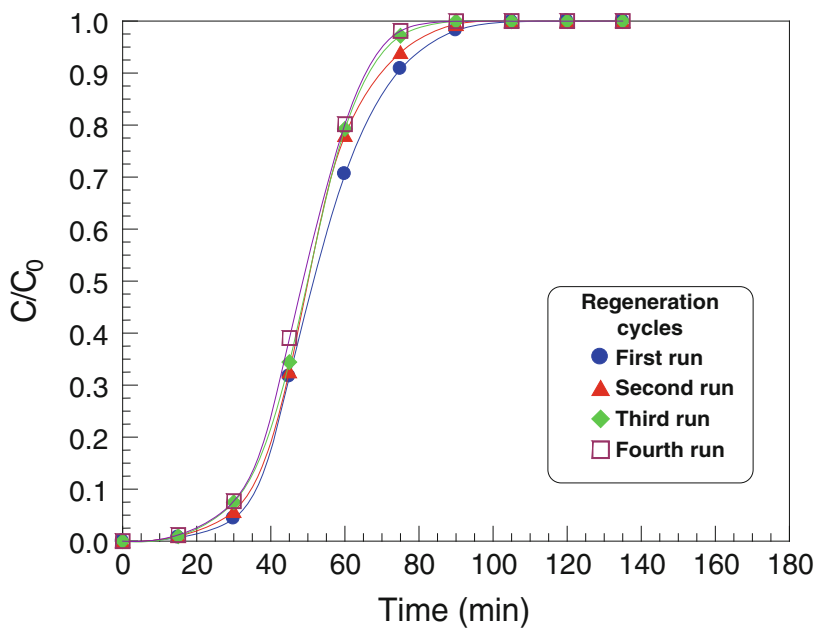

Fig. 8 Effect of successive desorption cycles on the breakthrough curves for the removal of $\mathrm{As}(\mathrm{V})$ ions at flow rate of $4 \mathrm{~mL} \mathrm{~min}^{-1}$ and bed height of $2.54 \mathrm{~cm}$

of the solute and the adsorption capacity of the resins. Thus, the critical bed height of the resin was recorded as $0.656 \mathrm{~cm}$. This indicates the high efficiency of the resin for the removal of $\mathrm{As}(\mathrm{V})$. The maximum adsorption capacities of the column at different bed heights are 1.458, 1.525 and 1.579 for $2.45,5.09$ and $7.64 \mathrm{~cm}$, respectively. The slight increase in the adsorption capacity with increasing bed height may be attributed to the better contact time of the $\mathrm{As}(\mathrm{V})$ anions with resin on the column, which positively affects the removal of $\mathrm{As}(\mathrm{V})$.

\section{Regeneration}

Sorption/desorption cycle runs were carried out for $\mathrm{As}(\mathrm{V})$ on $\mathrm{R}-\mathrm{Mo}$. The elution of the $\mathrm{As}(\mathrm{V})$ ions was performed using $50 \mathrm{~mL} 0.1 \mathrm{M}$ of orthophosphoric acid. As shown in Fig. 8, the breakthrough curves for recovery of $\mathrm{As}(\mathrm{V})$ (flow rate $4 \mathrm{~mL} \mathrm{~min}^{-1}$, bed height $2.54 \mathrm{~cm}$ ) showed no characteristic changes during successive cycles. This indicates that R-Mo has good performance for repeated use up to 3 cycles. The regeneration efficiency was found to be $96.85,99.81$ and $98.44 \%$ for 3 successive sorption/ desorption cycles, respectively.

Table 4 Data of column studies for the uptake of As(V) anions at different bed heights and flow rates

\begin{tabular}{|c|c|c|c|c|c|c|c|c|}
\hline Bed height $(\mathrm{cm})$ & Flow rate $\left(\mathrm{mL} \min ^{-1}\right)$ & $t_{\mathrm{s}}(\min )$ & $t_{\mathrm{b}}(\min )$ & $Q_{\text {max,exp }}\left(\mathrm{mmol} \mathrm{g}^{-1}\right)$ & $K_{\mathrm{a}}\left(\mathrm{L} \mathrm{mmol}{ }^{-1} \mathrm{~min}\right)$ & $N_{\mathrm{o}}\left(\mathrm{mmol} \mathrm{L}^{-1}\right)$ & $Z_{\mathrm{o}}(\mathrm{cm})$ & $R^{2}$ \\
\hline 2.54 & 2 & 150 & 15 & 1.4799 & & & & \\
\hline 2.54 & 4 & 106 & - & 1.4587 & & & & \\
\hline 2.54 & 6 & 90 & - & 1.4868 & 0.0097 & 798.1120 & 0.6560 & 1.00 \\
\hline 5.09 & 4 & 156 & 50 & 1.5252 & & & & \\
\hline 7.64 & 4 & 206 & 75 & 1.5798 & & & & \\
\hline
\end{tabular}




\section{Conclusion}

Molybdenum(VI)-loaded chitosan-TEPA resin was prepared and investigated. The resin obtained is characterized by a fast and a higher adsorption toward $\mathrm{As}(\mathrm{V})$ from aqueous medium at approximately $\mathrm{pH} 2$. The removal efficiency of $\mathrm{As}(\mathrm{V})$ ions was found to be highly dependent upon the acidity of the medium. The adsorption reaction was found to be endothermic with pseudo-second-order kinetics and proceeds according to Langmuir isotherm. The uptake value of $1.35 \mathrm{mmol} \mathrm{g}^{-1}$ was reported at $25^{\circ} \mathrm{C}$. Column studies give an account about the breakthrough points at different flow rates and bed heights. The critical bed height of the resin toward $\mathrm{As}(\mathrm{V})$ was found to be $0.656 \mathrm{~cm}$ at flow rate of $4 \mathrm{~mL} \mathrm{~min}^{-1}$. The regeneration efficiency of the loaded resin was found to be $96.85,99.81$ and $98.44 \%$ for 3 successive sorption/desorption cycles, respectively. This indicates that the resin has good performance for repeated use up to at least three cycles.

Acknowledgments The authors wish to thank Al-Fradouse Water Company, Sadat City, Egypt, for the support of this study.

\section{References}

Atia AA, Donia AM, Elwakeel KZ (2005) Adsorption behavior of non-transition metal ions on a synthetic chelating resin bearing iminoacetate functions. Sep Purif Technol 43:43-48

Atia AA, Donia AM, Elwakeel KZ (2008) Selective separation of mercury(II) using magnetic chitosan resin modified with Schiff's base derived from thiourea and glutaraldehyde. J Hazard Mater 151:372-379

Azizian S (2004) Kinetic models of sorption: a theoretical analysis. J Colloid Interface Sci 276:47-52

Balci B, Keskinkan O, Avci M (2011) Use of BDST and an ANN model for prediction of dye adsorption efficiency of Eucalyptus camaldulensis barks in fixed-bed system. Expert Syst Appl 38:949-956

Bundschuh J, Nath B, Bhattacharya P, Liu C-W, Armienta MA, López MVM, Lopez DL, Jean J-S, Cornejo L, Macedo LFL, Filho AT (2012) Arsenic in the human food chain: the Latin American perspective. Sci Total Environ 429:92-106

Couture R-M, Cappellen PV (2011) Reassessing the role of sulfur geochemistry on arsenic speciation in reducing environments. J Hazard Mater 189:647-652

Cui H, Li Q, Gao S, Shang JK (2012) Strong adsorption of arsenic species by amorphous zirconium oxide nanoparticles. J Ind Eng Chem 18:1418-1427

Duker AA, Carranza EJM, Hale M (2005) Arsenic geochemistry and health. Environ Int 31:631-641

Elwakeel KZ (2009) Removal of Reactive Black 5 from aqueous solutions using magnetic chitosan resins. J Hazard Mater 167:383-392

Elwakeel KZ (2010a) Environmental application of chitosan resins for the treatment of water and wastewater: a review. J Dispers Sci Technol 31:273-288

Elwakeel KZ (2010b) Removal of Cr(VI) from alkaline aqueous solutions using chemically modified magnetic chitosan resins. Desalination 250:105-112
Elwakeel KZ, Rekaby M (2011) Efficient removal of Reactive Black 5 from aqueous media using glycidyl methacrylate resin modified with tetraethelenepentamine. J Hazard Mater 188:10-18

Elwakeel KZ, Atia AA, Donia AM (2009) Removal of Mo(VI) as oxoanions from aqueous solutions using chemically modified magnetic chitosan resins. Hydrometallurgy 97:21-28

Elwakeel KZ, Abd El-Ghaffar MA, El-Kousy SM, El-Shorbagy HG (2012) Synthesis of new ammonium chitosan derivatives and their application for dye removal from aqueous media. Chem Eng J 203:458-468

Farnet AM, Qasemian L, Guiral D, Ferré E (2010) A modified method based on arsenomolybdate complex to quantify cellulase activities: application to litters. Pedobiologia 53:159-160

Freundlich HMF (1906) Uber die adsorption in losungen. Z J Phys Chem 57:385-470

Gang DD, Deng B, Lin L (2010) As(III) removal using an ironimpregnated chitosan sorbent. J Hazard Mater 182:156-161

Ghosh D, Datta S, Bhattacharya S, Mazumder S (2007) Long-term exposure to arsenic affects head kidney and impairs humoral immune responses of Clarias batrachus. Aquat Toxicol 81:79-89

Goswami A, Raul PK, Purkait MK (2012) Arsenic adsorption using copper (II) oxide nanoparticles. Chem Eng Res Des 90:1387-1396

Guan X, Du J, Meng X, Sun Y, Sun B, Hu Q (2012) Application of titanium dioxide in arsenic removal from water: a review. J Hazard Mater 215-216:1-16

Hansen HK, Nunez P, Grandon R (2006) Electrocoagulation as a remediation tool for wastewaters containing arsenic. Miner Eng 19:521-524

Ho YS, McKay G (1999) Pseudo-second order model for sorption processes. Process Biochem 34:451-465

Iqbal J, Wattoo FH, Wattoo MHS, Malik R, Tirmizi SA, Imran M, Ghangro AB (2011) Adsorption of acid yellow dye on flakes of chitosan prepared from fishery wastes. Arab J Chem 4:389-395

Jain CK, Singh RD (2012) Technological options for the removal of arsenic with special reference to South East Asia. J Environ Manag 107:1-18

Jekel R (1994) Removal of arsenic in drinking water treatment. In: Nriagu JO (ed) Arsenic in the environment, part I: cycling and characterisation. Wiley, New York, pp 119-132

Lagergren S (1898) About the theory of so-called adsorption of soluble substances. Kungliga Svenska Vetenskapsakademiens Handlingar 24:1-39

Langmuir I (1918) The adsorption of gases on plane surfaces of glass, mica and platinum. J Am Chem Soc 40:1361-1403

Lenoble V, Deluchat V, Serpaud B, Bollinger JC (2003) Arsenite oxidation and arsenate determination by the molybdene blue method. Talanta 61:267-276

Liao C-M, Shen H-H, Lin T-L, Chen S-C, Chen C-L, Hsu L-I, Chen C-J (2008) Arsenic cancer risk posed to human health from tilapia consumption in Taiwan. Ecotoxicol Environ Saf 70:27-37

Liu B, Lv X, Wang D, Xu Y, Zhang L, Li Y (2012) Adsorption behavior of As(III) onto chitosan resin with As(III) as template ions. J Appl Polym Sci 125:246-253

Lorenzen L, van Deventer JSJ, Landi WM (1995) Factors affecting the mechanism of the adsorption of arsenic species on activated carbon. Miner Eng 8:557-569

Mel'nik LA, Babak YV, Goncharuk VV (2012) Problems of removing arsenic compounds from natural water in the pressure driven treatment process. J Water Chem Technol 34:162-167

Miller SM, Zimmerman JB (2010) Novel, bio-based, photoactive arsenic sorbent: TiO2-impregnated chitosan bead. Water Res 44:5722-5729 
Min JH, Hering JG (1998) Arsenate sorption by Fe(III)-doped Alginate gels. Water Res 32:1544-1552

Mohan D Jr, Pittman CU (2007) Arsenic removal from water/ wastewater using adsorbents-A critical review. J Hazard Mater 142:1-53

Navarro P, Alguacil FJ (2002) Adsorption of antimony and arsenic from a copper electrorefining solution onto activated carbon. Hydrometallurgy 66:101-105

Ng JC, Wang J, Shraim A (2003) A global health problem caused by arsenic from natural sources. Chemosphere 52:1353-1359

Onnby L, Pakade V, Mattiasson B, Kirsebom H (2012) Polymer composite adsorbents using particles of molecularly imprinted polymers or aluminium oxide nanoparticles for treatment of arsenic contaminated waters. Water Res 46:4111-4120

Phan K, Sthiannopkao S, Kim K-W, Wong MH, Sao V, Hashim JH, Yasin MSM, Aljunid SM (2010) Health risk assessment of inorganic arsenic intake of Cambodia residents through groundwater drinking pathway. Water Res 44:5777-5788
Pontoni L, Fabbricino M (2012) Use of chitosan and chitosanderivatives to remove arsenic from aqueous solutions-a mini review. Carbohydr Res 356:86-92

Qi L, Xu Z (2004) Lead sorption from aqueous solutions on chitosan nanoparticles. Colloids Surf A 251:186-193

Qu S, Yang H, Ren D, Kan S, Zou G, Li D, Li M (1999) Magnetite nanoparticles prepared by precipitation from partially reduced ferric chloride aqueous solutions. J Colloid Interface Sci 215:190-192

Saha S, Sarkar P (2012) Arsenic remediation from drinking water by synthesized nano-alumina dispersed in chitosan-grafted polyacrylamide. J Hazard Mater 227-228:68-78

Will F, Yoe JX (1953) Colorimetric determination of molybdenum with mercaptoacetic acid. Anal Chem 25:1363-1366

Yamani JS, Miller SM, Spaulding ML, Zimmerman JB (2012) Enhanced arsenic removal using mixed metal oxide impregnated chitosan beads. Water Res 46:4427-4434 